\title{
Real time strain elastography for differentiation of solid renal masses
}

\author{
Fatih Mehmet Tezcan \\ Radiology Department, Health Sciences University, Umraniye Training and Research Hospital, Umraniye, Istanbul, Turkey
}

Received: 2020-07-03.

Accepted: 2020-08-02

This work is licensed under a Creative Commons Attribution 4.0 International License

J Clin Med Kaz 2020; 5(59):38-41

Corresponding author:

Fatih Mehmet Tezcan.

E-mail: fatihtezcan427@gmail.com

\begin{abstract}
Objective: The aim of this study was to investigate the diagnostic performance of real time strain elastography for evaluation of solid renal masses.

Material and methods: Forty two patients who were incidentally detected solid renal masses underwent Real Time Strain Elastography. Strain index value was detected for each lesion by dividing ROI of lesion to ROI of adjacent renal cortex. Strain index values and color encoding patterns of lesions and renal parenchyma were obtained. Mean strain index values and color encoding patterns for benign and malignant lesions were compared. Also by using ROC curve, cut-off value was obtained and diagnostic performance of method was evaluated.

Results: Any statistically significant difference of mean ages of patients was not found. Mean strain index value of malignant lesions were significantly higher than benign lesions. When cut-off value for strain index ratio was taken 0.3 , high diagnostic performance was obtained for differentiation of solid renal masses as benign or malignant.

Conclusion: Real time strain elastography can be useful for differentiation of solid renal masses as malignant or benign.
\end{abstract}

Key words: elastography, solid renal mass, kidney, strain

\section{Introduction}

Renal masses can be easily diagnosed by means of increased usage of imaging techniques. Renal cell carcinoma is the most seen malignant mass of kidney. It is nearly about $2 \%$ of all adult cancers. Renal oncocytoma and angiomyolipoma are the most common benign tumors of kidney. Renal cancers are usually diagnosed incidentally with ultrasonography (US) [1-3]. Then computerised tomography (CT) and/or magnetic resonance imaging (MRI) with contrast agent are performed. Conventionally, enhancing lesions in CT examinations are accepted as malignant and treated surgically. In one study, about $27 \%$ of enhancing small renal masses were found to be benign [4]. So, differentiation of lesions as benign or malignant is very important for management.

There are some disadvantages of CT and MRI. High dose of radiation in CT examination, claustrophobia in MRI, renal effects of contrast agents in both techniques are some of these. In spite of definitive diagnostic benefits of percutaneous biopsy, some complications can occur such as bleeding and arteriovenous fistula that can be life threatening. Also tumor seeding is the other disadvantage of biopsy. Thus, another noninvasive methods are needed for differentiation of bening and malignant lesions.
Real time strain elastography is a new technique which can assess tissue elasticity by manual compression and decompressions. Many papers which report the efficiency of elastography for solid lesions of breast [5], placenta [6] and salivatory glands [7] are available in the literature also for renal lesions [8,9]. In this prospective study we aimed to investigate the diagnostic performance of real time sonoelastography for evaluation of solid renal masses.

\section{Material and methods Patients and sonoelastography procedures}

In this prospective study 42 patients whowere referred to our institution for further evaluation of incidentally detected solid renal masses underwent sonoelastographic examinations. Obtained values of studies were compared with follow-up and histopathological results. Approval was obtained from the Ethics committee of our institution, written informed consent was given from participants.

Sonoelastographic examinations were made using US machine (General Elektric Logix E9; Milwaukee, WI, USA) and a convex probe (2.8-5 Megahertz) transabdominally in supine, right and left oblique positions. Examinations were performed by two observers 
(M.K. ve F.T.) who had sonoelastography experience of 2 years. These observers had no clinical information and did not know about histopathological results. The patients didn't eat anything at least 8 hours before examinations. Morphologic features of lesions such as size, shape, contour were examined in grey scale. Then sonoelastographic images were obtained by slight compression and decompression manually. Manual compression was accepted as sufficient, when at least 4 of 7 compression bars filled with green color. Mean examination time is five minutes for each patient. Cine mode was used to obtain and analyze images. RSE datas were formed by two observers in consensus. Firstly in grey scale, lesions were found, then ROI was placed in noncystic-noncalsific echogenic parts of lesions. Renal elasticity was displayed with a color overlay on B-mode sonography images ranged from blue (hard) to red (soft). Qualitative (M1) and semiquantitative (M2) methods were performed. In M1 method, lesions were classified to patterns (P) from soft to hard in 4 categories. Red or red-green color togetherness was categorized as soft (P1). Lesions which have nearly $50 \%$ blue areas were categorized as mild hard (P2), which have much more $50 \%$ blue areas were categorized as medium hard (P3) and absolute blue lesions were categorized as very hard (P4) [7]. P1 and $\mathrm{P} 2$ were accepted as benign and $\mathrm{P} 3$ and $\mathrm{P} 4$ were malignant. In M2 method, ROIs were placed in lesions and after renal parenchyma. Strain index value was detected for each lesions by dividing ROI of lesion to ROI of adjacent renal cortex.

By using ROC curves, cut-off values were investigated. Values higher than cut-off accepted as malignant and others were benign.

\section{Comparison with histopathologic results}

Sonoelastographic results were compared with histopathologic results. Pathologists had no information about RSE results. Lesions which were not evaluated histopatologically were accepted as benign if not changed in size at last 18 months follow-up.

\section{Statistical analysis}

Statistical analysis was made with SPSS software (ver.16). Patient characteristics were shown with minimum, maximum, means, frequencies and percentages. Independent sample t-test was used for comparisons of homogenic variances (mean ages in genders, mean ages in benign and malignant lesions and difference of mean strain indexes in benign and malignant lesions). Diagnostic performance of strain ratios for differentiating malignity and benignity were evaluated by using receiver operating characteristic (ROC) curves. The significance level was set at 0,05 .

\section{Results \\ Patient characteristics}

Mean age of patients was 58 (22-82). Mean age was 61 in men and 55 in women (Table 1). There was no statistically difference in mean ages between genders. Mean age of malignant lesions was 62 and benign was 53. There was no statistically difference in mean ages between malignant and benign groups.

\begin{tabular}{|c|c|c|c|}
\hline Table 1 & \multicolumn{3}{|c|}{$\begin{array}{l}\text { Mean age of patients in malignant and benign } \\
\text { groups are shown. }\end{array}$} \\
\hline Group & Mean & $\mathrm{n}$ & $\begin{array}{l}\text { Standart Devi- } \\
\text { ation }\end{array}$ \\
\hline Malignant & 62,19 & 21 & 13,15 \\
\hline Benign & 53,87 & 16 & 12,82 \\
\hline Total & 58,59 & 37 & 13,49 \\
\hline
\end{tabular}

$\mathrm{n}=$ number
Mean lesion size was $48 \mathrm{~mm}$ (benign lesions mean size $40 \mathrm{~mm}$ and malignant lesions mean size $54 \mathrm{~mm}$ ). There was no statistically difference in mean lesions sizes between malignant and benign groups.

Forty two (42) incidentally detected renal mass were examined. Six obese patients were excluded from study because of inadequate compression. In 3 patients who have multiple lesions, biggest ones of them were evaluated. One patient has 2 different lesions, both 2 lesions were evaluated. Thus, 37 lesions were assessed (Figure 1).

\section{Figure 1}

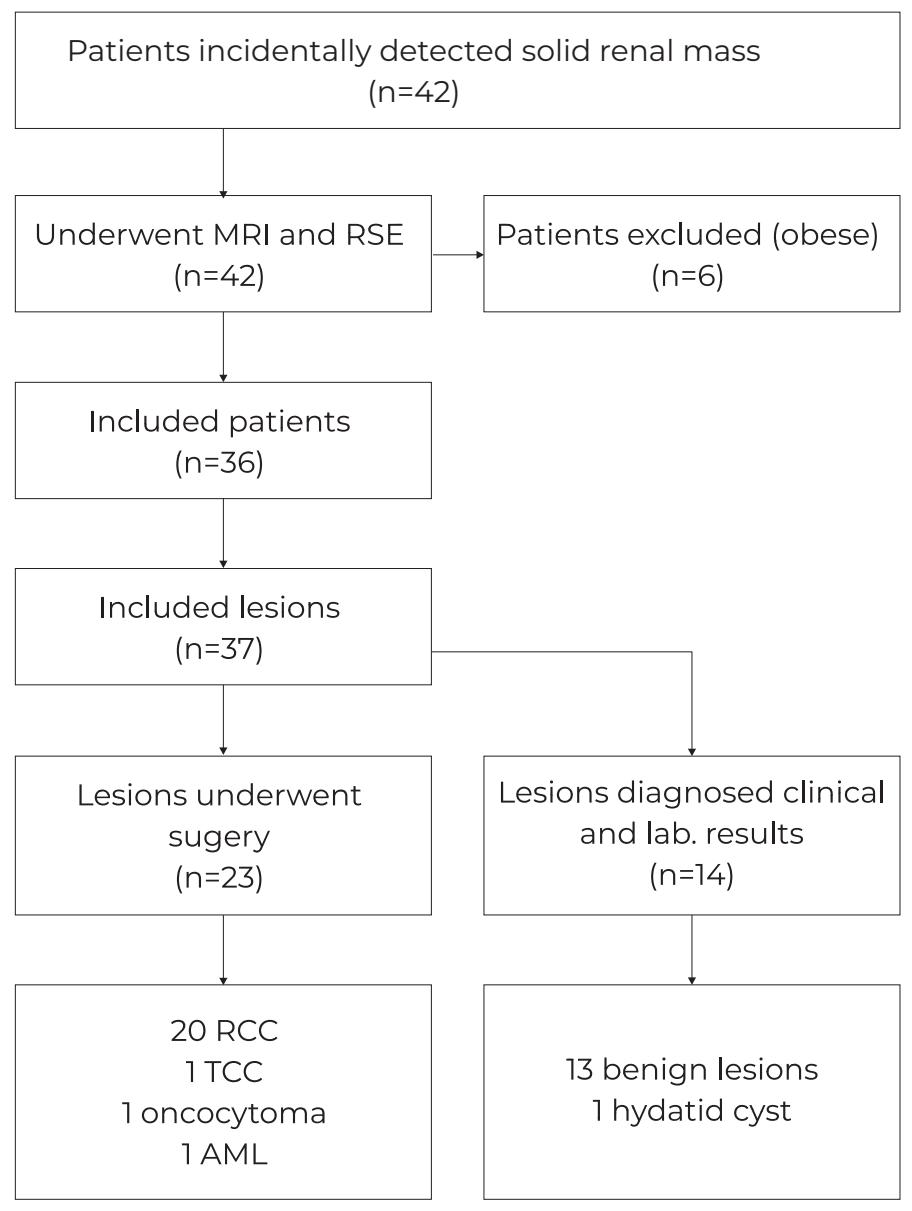

These lesions were clear cell RCC $(n=19)$, TCC $(n=1)$, chromofobe $\operatorname{RCC}(n=1)$, oncocytoma $(n=1)$, angiomyolipoma $(n=14)$ and hydatid cyst $(n=1)$. Twenty-three (23) lesions underwent surgery and had histopathologic results. 20 of these were renal cell carcinoma (RCC), 1 was transitional cell carcinoma (TCC), 1 was oncocytoma and the other was AML. All malign tumors and one angiomyolipoma were histopathologically diagnosed. There was no minimal fat angiomyolipoma in our study. Other angiomyolipomas and hydatid cyst were assessed with follow-up and laboratory results.

In M1 method 6 of 37 lesions (16.2\%) were categorized as P1, 9 (24.3\%) P2, 19 (51.4\%) P3 and 3 (8.1\%) P4. P3 was the most seen pattern; 17 of these $(89 \%)$ were malignant and 2 of these (11\%) benign. The most seen pattern in benign lesions was P2 and malignant was P3. According to M1 method sensitivity, specificity, positive and negative predictive value for detecting malignity were found $95 \%, 87 \%, 90 \%$ and $93 \%$.

In M2 method, 1 lesion ( $2 \%$ ) was found harder than renal 
cortex and 36 lesions (98\%) were softer. Strain index values were between 0.4-1.1 (mean 0,63) in malignant and between 0.1-0.9 (mean 0,28) in benign lesions. Statistically significant differences were found between mean values of them $(p<0.001)$ (Figure 3).

\section{Figure 2}

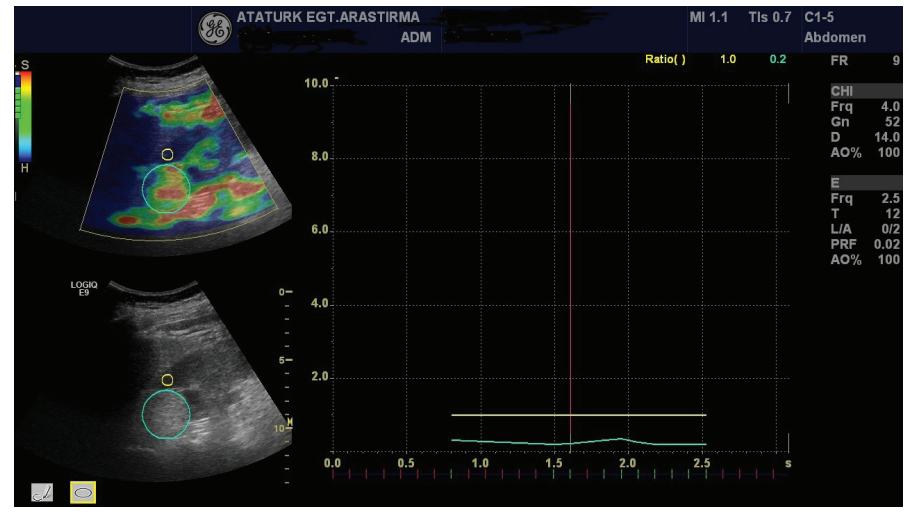

Highest strain index were detected in RCCs. This value differ between malignant and benign lesions significantly. According to M2 method, cut-off value was taken 0.3. For values bigger than 0.3 ; positive and negative predictive value for detecting malignant lesion were found $80 \%$ and $100 \%$, sensitivity and specificity were $100 \%$ and $68.7 \%(\mathrm{p}<0.001)$ (Figure 4). (Area under curve-AUC:0.899). For other values sensitivity and specificity that could detect benign lesions were $68.7 \%$ and $100 \%(\mathrm{p}<0.001)$ (AUC:0.899).

\section{Figure 3}

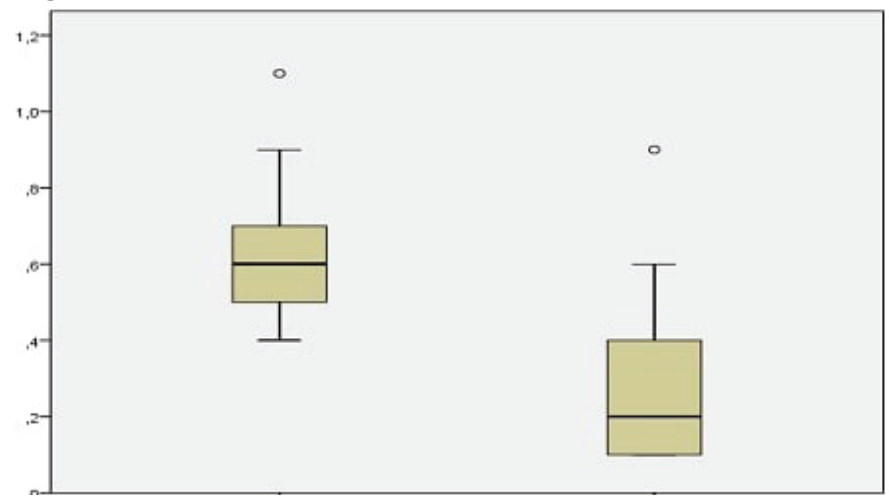

\section{Figure 4}

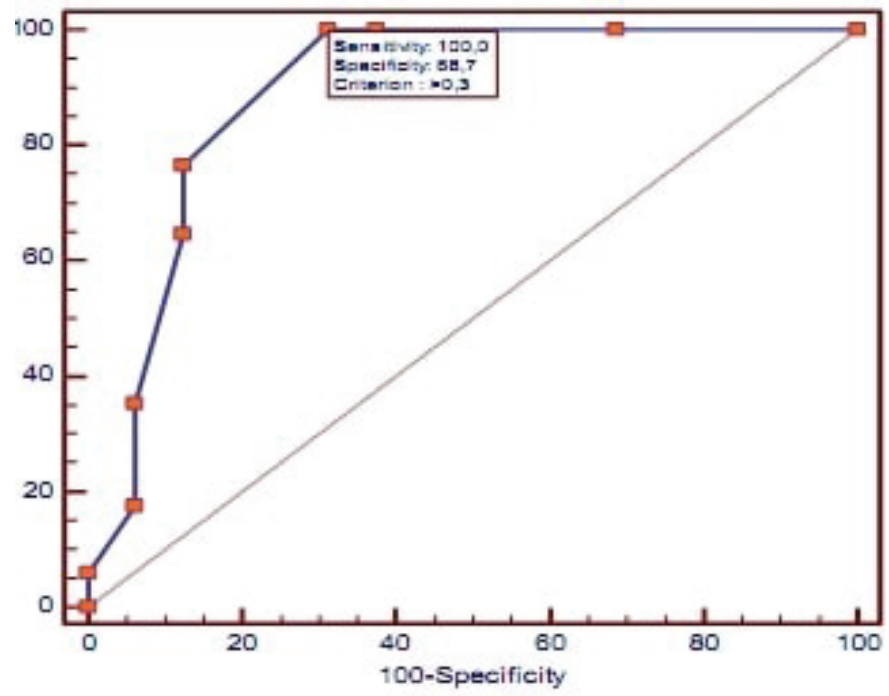

Elastographic pattern of AML in right kidney was 2 and strain index ratio was measured 0.2 (Figure 2).

\section{Discussion}

US is first but not only method for detecting and characterization of renal solid lesions especially tumors. Differentiation of malignant and benign lesions is nearly impossible in grey scale. There are some findings which were seen either malignant or benign lesions, so other methods are needed for diagnosis usually [10].

RSE is a recently developed sonographic technique for evaluating tissue elasticity by using softwares. RSE is needed manual compression and decompression versus shear wave elastography. For this reason, measuring the elasticity of visceral organs is difficult. Also RSE can not provide tissue elasticity value in $\mathrm{kPa}$.

In the literature, RSE could differentiate malignant lesions from benign ones in cervical lymph nodes and thyroid nodules $[11,12]$. The main idea was that; big nucleus-small cytoplasms cells are dominant in malignant tissues and tumors are getting harder as compared with normal tissues [13]. Researches in renal pathologies are firstly based on animal and in vitro laboratory studies [14-16].

Gallotti et al evaluated normal elasticity of upper abdominal viscera by using Acoustic Radiation Force Impulse (ARFI) technique. Shear wave in renal parenchyma was found to be very high $(2.24 \mathrm{~m} / \mathrm{s})$ [17]. This means that renal parenchyma is very hard. Arda et al found that mean elasticity of renal cortex was 5.0 kilopascal $(\mathrm{kPa})$. Renal pelvis elasticity was found 23 $\mathrm{kPa}$ and elasticity of it was higher than cortex [18]. This result is compatible with results in study of Gallotti et al.

Clevert et al. evaluated the effectiveness of contrast enhanced US and ARFI for no-etiology known renal tumors by comparing histological findings. In the study of 15 lesions, reference ROIs were put on parenchyma and measurements were made. Shear waves were found between 1.31 and $4.40 \mathrm{~m} / \mathrm{s}$; also measurements of lesion ROIs were found between 1.60 and 3.42 $\mathrm{m} / \mathrm{s}$. Papillary tumors were found to be harder than parenchyma. In our study, 4 papillary RCC lesions' lesion-parenchyma strain index values were higher, stiffness were lesser than kidneys; this was not compatible with their study. In the study of Clevert et al, shear wave rates of malignant lesions were reported to be close to rates in kidney parenchyma [19]. In our study most of malignant lesions were found to be softer than renal parenchyma, so these results of our study are compatible with this study.

Clinical studies which were written about renal elasticity are mostly with ARFI and strain elastography, also a few newly studies with shear wave elastography [20,21].

Onur et al, by using strain elastography, found lower strain indexes in benign renal masses. Malignant lesions were found 2,8 times stiffer than benign ones. They also compared RCC and AML lesions, then found significantly different elasticity between them [20]. In our study, malignant lesions were found 2,2 times stiffer than benign lesions. Aydin et all, by using shear wave elastography, found that malignant tumors had minimal but not significantly higher elasticity values. According to them this can be possibly explained by using different US equipment. They also found that RCC lesions had higher elasticity-1,8 times stiffer-than angiomyolipomas. Also results of these study are compatible with our study.

Also by using M1 method, sensitivity increases but specificity decreases, compared with M2 method. Specificity of M2 is higher for distinguishing benign lesions. RSE can be said useful for distinguishing benign lesions especially AMLs from malignant lesions.

There are some limitations of this study. Firstly, number 
of lesions are relatively small and variety of diagnosis decreases and effectiveness can be evaluated for some lesions. Secondly, strain index values can be measured but shear waves can not be measured directly and stiffness levels of tissues can not be measured as $\mathrm{kPa}$. Because of this, stiffness in reference ROI can not be calculated numerically. Color scale evaluation which made according to differences of stiffness ratios of lesion and reference area can not be enough. The other one is, perfect compression and qualitative RSE examination is probable with holding breath. The other limitation is evaluation of lesions by only two observers. The most important limitation of this study is that some of the lesions has no histopathologic diagnosis. Because of this reason sensitivity and specificity of method can not be generated.

\section{Conclusion}

Real time strain elastography can be useful for differentiation of solid renal masses as malignant or benign. Strain index values of benign lesions are lesser than malignant ones. High diagnostic performance of sonoelastography is seen for benign-malignant differentiation of solid renal massses. Real time strain elastography must be performed after grey scale sonographic examinations for renal masses.

Disclosures: There is no conflict of interest for all authors.

\section{Funding: none}

\section{References}

1. Jemal A, Siegel R, Ward E, Murray T, Xu J, Thun MJ. Cancer statistics 2007. CA Cancer J Clin. 2007; 57:43-66. https://doi.org/10.3322/ canjclin.57.1.43

2. Luciani LG, Cestar R, Tallarigo C. Incidental renal cell carcinoma-age and stage characterization and clinical implications: study of 1092 patients. Urology. 2000; 56:58-62. https://doi.org/10.1016/S0090-4295(00)00534-3

3. Stakhovskyi O, Yap SA, Leveridge M, Lawrentschuk N, Jewett MA. Small renal mass: what the urologist needs to know for treatment planning andassessment of treatment results. AJR Am J Roentgenol. 2011; 196:1267-1273. https://doi.org/10.2214/AJR.10.6336

4. Kutikov A, Fossett LK, Ramchandani P, et al. Incidence of benign pathologic findings at partial nephrectomy for solitary renal mass presumed to be renal cell carcinoma on preoperative imaging. Urology. 2006; 68:737-740. https://doi.org/10.1016/j.urology.2006.04.011

5. Chang JY, Moon JH, Koh SH, Park SY, Lee KS. Clinical Application of ShearWave Elastography in Breast Masses. Iran J Radio. 2017; 14(1):e39585. https://doi.org/10.5812/iranjradiol.39585

6. Altunkeser A, Alkan E, Günenç O, Tolu I, Körez MK. Evaluation of a Healthy Pregnant Placenta with Shear Wave Elastography. Iran J Radio. 2018; 16(1):e68280. https://doi.org/10.5812/iranjradiol.68280

7. Dumitriu D, Dudea S, Botar-Jid C, Baciut M, Baciut G. Real-time sonoelastography of major salivary gland tumors. AJR Am $J$ Roentgenol. 2011; 197:924-930. https://doi.org/10.2214/AJR.11.6529

8. Onur MR, Poyraz AK, Bozgeyik Z, et al. Utility of semiquantitative strain elastography for differentiation between benign and malignant solid renal masses. J Ultrasound Med. 2015; 34(4):639-647. https://doi.org/10.7863/ultra.34.4.639

9. Aydin S, Yildiz S, Turkmen I, Sharifov R, Uysal O, Gucin Z, ArmaganA, Kocakoc E. Value of shear wave elastography for differentiatingbenign and malignant renal lesions. Med Ultrason. 2018; 1:21-26. https://doi.org/10.11152/mu-1161

10. Pallwein-Prettner L, Flöry D, Rotter CR, et al. Assessment and characterisation of common renal masses with CT and MRI. Insights Imaging. 2011; 2:543-556. https://doi.org/10.1007/s13244-011-0116-1

11. Lyshchik A, Higashi T, Asato R, et al. Thyroid Gland Tumor Diagnosis at US Elastography. Radiology. 2005; 237:202-211. https://doi. org/10.1148/radiol.2363041248

12. Lyshchik A, Higashi T, Asato R, et al. Cervical Lymph Node Metastases: Diagnosis at Sonoelastography-Initial Experience. Radiology. 2007; 243 :258-267. https://doi.org/10.1148/radiol.2431052032

13. Kumar V, Cotran RS, Robbins Sl. Basic Pathology 6th ed. Ankara: Çevikbaș U. 2000; 475-476.

14. Lee JW, Lorenzo EI, Ahn B, et al. Palpation device for the identification of kidney and bladder cancer: a pilot study. Yonsei Med J. 2011; 52:768-772. https://doi.org/10.3349/ymj.2011.52.5.768

15. Derieppe M, Delmas Y, Gennisson JL, et al. Detection of intrarenal microstructural changes with supersonic shear wave elastography in rats. Eur Radiol. 2012; 22:243-250. https://doi.org/10.1007/s00330-011-2229-9

16. Emelianov SY, Lubinski MA, Weitzel WF, Wiggins RC, Skovoroda AR, O'Donnell M. Elasticity imaging for early detection of renal pathology. Ultrasound Med Biol. 1995; 21:871-883. https://doi.org/10.1016/0301-5629(94)00146-5

17. Gallotti A, D'Onofrio M, Pozzi Mucelli R. Acoustic Radiation Force Impulse (ARFI) technique in ultrasound with Virtual Touch tissue quantification of the upper abdomen. Radiol Med. 2010; 115:889-897. https://doi.org/10.1007/s11547-010-0504-5

18. Arda K, Ciledag N, Aktas E, Aribas BK, Köse K. Quantitative assessment of normal soft-tissue elasticity using shear-wave ultrasound elastography. AJR Am J Roentgenol. 2011; 197:532-536. https://doi.org/10.2214/AJR.10.5449

19. Clevert DA, Stock K, Klein B, et al. Evaluation of Acoustic Radiation Force Impulse (ARFI) imaging and contrast-enhanced ultrasound in renal tumors of unknown etiology in comparison to histological findings. Clin Hemorheol Microcirc. 2009; 43:95-107. https://doi. org/10.3233/CH-2009-1224

20. Onur MR, Poyraz AK, Bozgeyik Z, et al. (2015) Utility of semiquantitative strain elastography for differentiation between benign and malignant solid renal masses. J Ultrasound Med. 34(4):639-647. https://doi.org/10.7863/ultra.34.4.639

21. Aydin S, Yildiz S, Turkmen I, Sharifov R, Uysal O, Gucin Z, Armagan A, Kocakoc E. Value of Shear Wave Elastography for Differentiating Benign and Malignant Renal Lesions. Med Ultrason. 2018;1(1):21-26. doi: 10.11152/mu-1161. https://doi.org/10.11152/mu-1161 